\title{
Europa: una historia pendular de unión y división
}

\section{Europe: a Back and Forth Story of Union and Division}

\author{
Alberto Gil Ibáñez ${ }^{1}$ \\ Escritor y Ensayista (España)
}

Recibido: 04-09-20

Aceptado: 30-09-20

\section{Resumen}

Este artículo analiza la historia de Europa desde un triple punto de vista. Por un lado, valora cómo llegó a construirse la cultura europea y su integración política, y cómo fácilmente pudo desaparecer o pasar a la irrelevancia. Por otra, se describe el vaivén de fuerzas centrípetas y centrífugas que han jugado sus cartas en el continente a lo largo de los siglos. En tercer lugar, se analiza el papel, a menudo ignorado, que en todos esos procesos ha jugado España. Por último, se estudian las amenazas internas que dominan el momento presente, así como las lecciones que podemos sacar del pasado para lograr un nuevo renacimiento cultural europeo, evitando así una decadencia a la que parecemos estar abocados.

\footnotetext{
1 (alberto.gibanez@gmail.com). Alberto G. Ibáñez ha sido profesor de Derecho Europeo en la Universidad S Pablo-CEU. En la actualidad es miembro del grupo de Reflexión del Instituto Universitario de Estudios Europeos. Doctor en Derecho por el Instituto Universitario de Florencia (Italia) y Doctor (premio extraordinario) en Ciencias de las Religiones por el Instituto Universitario de Ciencias de las Religiones (Universidad Complutense). Pertenece al Cuerpo Superior de Administradores Civiles del Estado y es Diplomado en altos estudios de la Defensa (CESEDEN). Ha publicado numerosos artículos y más de diez libros que abarcan la reforma institucional, el Derecho, la Ciencia Política o la Historia. De ellos cabe destacar el libro colectivo (que coordinó junto a Ramón Marcos): A favor de España: el coste de la ruptura (2014) donde participaron Fernando Savater o Mario Vargas Llosa, La Conjura silenciada contra España (2016) y La Leyenda Negra. Historia del odio a España (2018). Entre sus artículos especializados destacan: "Why Nations Fail. The Relevance of Stability and Culture for European and Global Security", "El enemigo interno de Occidente: una hidra de cinco cabezas. ¿Existe (o debe existir) una cultura europea? Hacia un renacimiento cultural: ¿Procedimientos o valores compartidos? ¿Existe un derecho ilimitado a crear nuevos Estados-nación? Su último libro se titula: La Guerra cultural. Los enemigos internos de España y Occidente, ed. Almuzara, octubre, 2020.
}

ORCID: https://orcid.org/0000-0001-5487-0659. 
Palabras-clave: Historia de Europa, integración, valores, desintegración, decadencia, renacimiento

\begin{abstract}
This article analyzes the History of Europe from a threefold point of view. On the one hand, it evaluates how European culture and political integration came to be built, and how it could easily disappear or become irrelevant. On the other, it describes the swing of centripetal and centrifugal forces that have played their cards in Europe over the centurie. Thirdly, it analyzes the role, frecuently underestimated, played by Spain in these processes. Finally, it examines the internal threats of the present moment and the lessons we can draw from the past in order to achieve a new European cultural renaissance, avoiding a decline to which we seem to be heading.
\end{abstract}

Key-words: History of Europe, Integration, Values, Disintegration, Decadence, Renaissance

"el pueblo que no aprende de su Historia
está condenado a repetirla"
Jorge Santayana

"lo único que podemos aprender de la Historia es que no aprendemos nada de ella" G.W.F. Hegel

\title{
1. Auge y decadencia: cómo nació Europa y cómo pudo llegar a no ser
}

\section{1 ¿Qué es Europa?}

No es una pregunta sencilla. Es un concepto que no siempre ha existido y su cultura o su civilización han evolucionado desde la Edad Media hasta nuestros días (Elías: 2016). La respuesta puede variar además si aplicamos un enfoque geográfico, cultural, histórico, ideológico, religioso... Por tanto se trata de una cuestión compleja que como tal no admite respuestas sencillas sino que demanda un enfoque pluridisciplinar.

Geográficamente, en los tiempos de Anaximandro o Sócrates Europa abarcaba desde las columnas de Hércules (Gibraltar) hasta el río Phase (o Rioni), que desembocaba en el Mar Negro. El primero que utilizó el nombre de Europa fue Hesíodo en su Teogonía, citada como una diosa, una de las tres mil hermanas oceánidas. El primero en describirla frente a Asia fue Hipócrates. A 
principios del siglo $\mathrm{V}$ antes de nuestra era Herodoto le da autonomía histórica (libro dedicado a Melpomemea) y el poeta latino Claudius Claudiano, siendo pagano, ya identificaba a sus enemigos en el moro Gildon y el bárbaro Alarico. Desde un punto de vista mítico, al mito del "rapto de Europa" se añade una división del mundo que surgiría paradójicamente tras el diluvio universal, cuando tres hijos de Noé poblaron el mundo: Sem iría a Asia (de ahí lo de semitas), Cam a África y Jafet a Europa, dando así lugar a tres estirpes diferenciadas, aunque de América y Australia no se dijera entonces nada.

Desde el punto de vista cultural-intelectual fueron los mismos griegos los que le dieron sentido una vez les quedó claro que no podían abarcar y dominar Asia. Posteriormente, muchos otros darían soporte a la idea de Europa como comunidad política y religiosa: Comenius, 1592-1670 (que identificaba Europa-Cristiandad con el mundo), el Abad de Saint-Pierre (1658-1743), G.W. von Leibniz (1646-1716), quien entre otras cosas consideraba que Rusia debía de ejercer de puente entre Europa y China con vistas a una unión de civilizaciones, Heinrich Heine (1799-1856), Baltasar Gracián (1601-1658), Victor Hugo, (1802-1885), Kant, Sant-Simon, Voltaire, Donoso Cortés (18091853), Unamuno (1864-1936), Jacques Maritain (1882-1973), Karl Jaspers (1883-1969), José Ortega y Gasset (1883-1955)..., por no hablar de precedentes a menudo ignorados como san Isidoro de Sevilla (560-636) y sus Etimologías o La Chronica Mundi que inspiró fuertemente a San Beda el Venerable..

Lo que hoy entendemos por "Europa" surge con la filosofía greco-latina y el derecho romano, se consolida con el cristianismo como religión (que integra a Oriente a través de la tradición judía), se expande hacia América, principalmente por España, y hacia los Urales por Rusia, sigue con el humanismo como sustrato ideológico que se forma por los filósofos-teólogos de la Escuela de Salamanca, continúa y se seculariza con la ilustración francesa y la filosofía alemana, y acaba con el liberalismo económico y político y el triunfo final de la ciencia y la tecnología. Políticamente su máximo logro ha sido el Estado social y democrático de derecho, donde se consigue un equilibrio entre lo mejor del socialismo y del liberalismo, junto con los derechos humanos, las libertades públicas, y el respeto a la ley y a la Constitución como norma suprema. Ha traído grandes obras de arte, la música clásica, las catedrales góticas, el pensamiento metafísico, el humanismo cristiano, la democracia, la separación de poderes y el estado de derecho como modelo político, la economía de mercado como modelo económico, y en un sistema de protección social como modelo compensador de desigualdades.

Sin embargo, aunque el concepto de civilización se relaciona a menudo con la herencia europea, ni ésta tiene el monopolio ni ha sido la primera. Los primeros homínidos de paso erecto "aparecerían" en África hace 5 millones de años y solo llegarían a Europa hace un millón y medio, debiendo esperar 
bastante más (hace unos 37.000 años) para que tomara forma el Homo sapiens. El proceso civilizatorio surge en torno a la escritura hace unos 6.000-7.000 años en el triángulo fértil y la cuenca del río Nilo, precisamente en Egipto, Mesopotamia y Persia (Oriente) y llega a Europa a través de Grecia y Roma; aunque nuevos descubrimientos en Bulgaria, Grecia y Alemania hablen de un antecesor más remoto (más de 7 millones de años) y cercano (de la propia Europa) $)^{2}$.

La civilización que apellidamos europea y moderna no es oriental ni occidental. Es sencillamente el resultado de un proceso histórico, integrador, que comenzó en oriente, que continuó luego en el Mediterráneo, y siguiendo los pasos del sol, ha dado la vuelta al Mundo. Europa proviene pues de Oriente y no es ajena a África. Sus habitantes proceden, como el resto, de África y su cultura de Asia, madre de todas las grandes religiones, como recuerda Gonzague de Reynold. Hasta el punto de que Paul Valéry llegó a considerarla un apéndice de Asia y en el mito griego los pueblos de Europa debían sus orígenes a una princesa asiática. De hecho, como señala A. Padgen "los persas y los partos (las dos grandes razas asiáticas y "bárbaras" del mundo antiguo) [...] en sus orígenes eran muy parecidos a los griegos y, con ciertas reservas, a los romanos, que al atribuirse una estirpe mítica en Troya se habían convertido a sí mismos también en un pueblo originalmente asiático" (Padgen: 2011, 14). Por su parte, para Montanelli "la historia de Europa empieza en China", no solo por los paralelismos que cabe hacer entre los imperios chino y romano, sino porque ambos fueron atacados por la misma tribu de bárbaros nómadas: los Jong-Nu o Hunos (1966, 15 y 16).

Por tanto, en un principio no estaba claro que Europa y Asia (o África) fueran algo distinto, y de hecho hubo varios intentos de unirlas, tanto por parte europea (e.g. Imperio romano o Alejandro Magno) como asiática (e.g. reyes persas Darío y Jerjes, imperio árabe y otomano o Gengis Kan), aunque siempre tratando de imponer una parte al todo. Para construir el concepto de una Europa cohesionada y no un mero territorio-continente, paradójicamente, se sigue el mismo proceso de construcción de las grandes naciones: una religión que le da cohesión cultural y social interior y un enemigo exterior (real o supuesto) que justifica su necesidad para defenderse del invasor. Al menos desde las guerras médicas, y en concreto desde la victoria en Maratón (490 a.n.e.), considerada por Stuart Mill y Lord Byron como un momento constitutivo europeo, donde la libertad y democracia (en realidad en ese momento solo griegas) se impusieron a la tiranía asiática, como diez años más tarde ocurriría también en la célebre batalla de Salamina, donde para G. F. Hegel se impuso la personalidad libre europea al despotismo oriental, la fuerza espiritual a la masa material (Padgen:

\footnotetext{
https://www.spiegel.de/wissenschaft/mensch/spektakulaerer-funderste-aufrecht-gehendemenschenaffe-kam-aus-bayern-a-1295117.html.
}

Araucaria. Revista Iberoamericana de Filosofia, Politica, Humanidades y Relaciones Internacionales, año $22, \mathrm{n}^{\circ} 45$. Tercer cuatrimestre de 2020. Pp. 527-548. ISSN 1575-6823 e-ISSN 2340-2199 https://dx.doi.org/10.12795/araucaria.2020.i45.22 
2011, 43 y 52). De forma similar, los procesos de nacionalización de las grandes potencias europeas (comenzando por Francia y Reino Unido) se llevaron a cabo sobre la base de constituir religiones nacionales, en realidad versiones del cristianismo susceptibles de ser controladas por el poder político (en el caso francés la revolución operó como religión laica unificadora) y la "necesidad" de hacer frente a España y su poder en el mundo (Marías: 2010, 159 y 160) . $^{3}$ Una de las pocas excepciones a esta forma de proceder ha sido precisamente España, que no ha contado con un enemigo exterior claro en su proceso de construcción nacional, y que a pesar de que tuvo otras opciones (e.g. arrianismo y erasmismo) optó por seguir fiel a la religión "católica", es decir, universal, que controlaba Roma.

No obstante, más allá del conflicto griego-persa, Europa tomaría conciencia como potencial unidad cuando se enfrenta al mundo árabe (nuevo enemigo exterior) con ocasión de la batalla de Poitiers en 732, aunque también podríamos situar ese momento un poco más tarde: en 1212 en la batalla de las Navas de Tolosa. Carlomagno daría forma política a esa idea de una Europa unida con el primer imperio considerado europeo (768-814), en realidad más por sus cronistas que por sí mismo, apegado como sus sucesores al viejo concepto de sacro imperio "romano". En todo caso, la tesis dominante defiende que la cultura europea "occidental" surge cuando Carlomagno logró que la Iglesia unitaria se impusiera sobre las territoriales, consiguiendo así que aquélla se fuera distinguiendo poco a poco de la Europa bizantina, greco-ortodoxa, orientalizada, distinción que se fortalecería con las cruzadas (von Martin: 1970, 17 y 46). Luego volveremos sobre esta cuestión.

Esta tesis franco-germana olvida que fueron los países del sur de EuropaGrecia, Italia, España y Portugal- los que crearon el entramado político, moral y filosófico sobre el que luego se construiría Europa y los que posibilitaron que fuera ésta, y no otras regiones competidoras, la que se extendiera y dominara otros continentes. Eso pasó, por ejemplo, a través de la Escuela de Traductores, que logró reintroducir el pensamiento griego añadiendo importantes aportaciones árabes, sobre todo en el campo de las matemáticas y la medicina, cuando Europa estaba huérfana de ideas y vivía una clara decadencia cultural, sobre la que se suele pasar de puntillas y que todavía hoy nos sorprende. $\mathrm{O}$

\footnotetext{
3 Thomas Carlyle consideraría a la revolución francesa como el tercer acto de la revolución protestante iniciada por Lutero (la segunda sería el puritanismo). De hecho, el cristianismo operaría como la primera y casi única revolución de occidente de la que beberían el resto. John Gray (2008), uno de los filósofos políticos contemporáneos más relevantes, ha sostenido que todas las utopías occidentales, a pesar de presentarse como ateas o paganas, se han fundamentado siempre en la visión apocalíptica o milenarista procedente de la religión cristiana. No es por ello extraño que los mayores diplomáticos de la Revolución francesa, Talleyrand, Sieyés y Fouché, provinieran de la escuela de la Iglesia, y que los mayores validos de Francia, fueran cardenales. En este sentido, la historia de Europa también se puede leer como una permanente dialéctica entre cristianismo formal (que se conforma con los aspectos formales) y real (que apunta a los aspectos sustanciales del mensaje cristiano).
} 
con la Escuela de Salamanca y sus aportaciones en el campo del derecho o la economía, entre otras. En este sentido, el dominico Francisco de Vitoria (14801546) fue el primero que se cuestionó (en su libro De Indis) la legitimidad de la guerra si favorecía los intereses de un país en detrimento de los del mundo o de la Cristiandad en particular, creando junto a Suárez el derecho de gentes.

\subsection{De cómo Europa pudo fácilmente llegar a no ser}

El proceso arriba descrito muestra que la construcción de la "idea" de Europa fue algo complejo lleno de obstáculos y dificultades. Por de pronto, si los persas no hubieran sido frenados por los griegos, la Europa que hoy conocemos simplemente sería otra. Existen igualmente otros tres momentos que habrían determinado, incluso con mayor relevancia, la desaparición de Europa o que ésta hubiera pasado fácilmente a la irrelevancia política y cultural, o que de potencia colonizadora se hubiera convertido en territorio colonizado... por otros que podrían haber impuesto su poder, su cultura, su lengua, religión y costumbres.

En primer lugar, si los pueblos 'bárbaros' del norte - esos mismos que pasan hoy por ser los más civilizados y modernos del mundo- en su proceso de expansión violenta no se hubieran convertido al cristianismo (no en vano "Cristiandad" fue el primer nombre de Europa), se habría perdido con casi total seguridad las trazas de la civilización europea que hoy conocemos, ya que fue la vía religiosa, a pesar de las críticas recibidas, la que ejerció de basamento primero y firme de las otras dos patas de la cultura europea: la filosofía griega y el derecho romano. En segundo lugar, si Europa hubiera sido conquistada por el mundo árabe, como era su intención desde el primer momento -y no se hubiera logrado parar esa estrategia en Poitiers, Navas de Tolosa o Lepanto- el resultado habría sido la expansión final de la nación árabe como ocurrió con otros territorios, incluida por ejemplo la propia Persia (hoy Irán) con culturas y religiones pre-arábicas de gran prestigio y altura intelectual, en este caso el zoroastrismo.

No podemos detenernos aquí en el curioso contraste entre una Europa inmersa en tinieblas de ignorancia que olvidaba sus orígenes y sus ancestros (griegos) y la sorprendente transformación de un islam formado en su mayoría por pastores, beduinos nómadas y toscos guerreros en su gran parte analfabetos, lectores en todo caso de un solo libro (el Corán) - que es el mundo que Mahoma deja cuando muere (632)-, en una fuente del saber moderno a partir del gran califa Moavia. Se trata de un momento clave donde deciden recoger ese mismo pensamiento griego (con fabulosas traducciones del griego al árabe) que los europeos (salvo los bizantinos) despreciaban o habían perdido -en un momento que nos recuerda al presente-, llegando a incluso mejorar dicho legado en las 
matemáticas (el número cero y el álgebra son creaciones árabes), la química (el alambique), la biología o la medicina. Si bien no todos los califas tendrían una sensibilidad semejante pues es famosa la frase del califa Omar (640) que dirigió a su general a propósito de la destrucción de la biblioteca de Alejandría:

Si esos libros están de acuerdo con el Corán, no tenemos necesidad de ellos, y si éstos se oponen al Corán, deben ser destruidos.

Lo más curioso es que gracias a la invasión por el islam de un país europeo (España), toda Europa pudo recupera la "civilización perdida", el saber de sus ancestros incluso aumentado a través de la escuela de Traductores de Toledo. Y resulta igualmente paradójico que, una vez España logra expulsar al imperio árabe de sus tierras, aquél perdiera rápidamente su antiguo esplendor, entrando en una nueva decadencia cultural que le haría volver a sus orígenes más dogmáticos, proceso que incomprensiblemente dura en muchos lugares hasta el día de hoy".

Un tercer momento que ejerció de "gozne de la historia", que suele pasar desapercibido pero en el que Europa se jugaba, probablemente sin saberlo, su ser o no ser, fue el hecho de que fuera una potencia europea (España), y no China, por ejemplo, la que llegase primero a América, mientras otra nación ibérica (Portugal) se expandía por África y llegaba a las Indias. En 1492 el continente asiático tenía todas las de ganar para alcanzar la hegemonía mundial. Europa era todavía un lugar despreciado, atrasado e ignorado. La India, el islam, China y el resto de Asia oriental la superaban en riquezas, arte e inventiva. Sólo la apertura hacia el Atlántico y la incorporación del continente americano a Occidente pudo parar ese proceso (Fernández-Armesto: 2010, 12 y 36). ¿Y qué hubiera ocurrido con el cristianismo? Probablemente habría pasado a ser una religión regional intrascendente frente al islam o a las religiones orientales que se habrían expandido por el mundo.

En términos históricos se habla del resurgir de Europa con la Edad Moderna a finales del siglo XV o principios del XVI. Hay una fecha cierta: 1492. ¿Por qué? Porque en ese año el habitante del planeta tomó conciencia de sí mismo, de qué era la humanidad y del lugar dónde vivía, a través de la conexión entre los dos hemisferios del mundo que logró la expedición española encabezada por Colón. Sin embargo, desde un enfoque centroeuropeo se opta por citar en su lugar otras fechas: 1450, que conmemora la invención de la imprenta, acontecimiento sin duda relevante pero nada comparable al descubrimiento de América si no fuera tal vez porque sirvió esencialmente para difundir con una asombrosa eficacia la leyenda negra anti-española; 1453, que conmemora la caída de Constantinopla, y por tanto curiosamente la destrucción de Europa; y 1517, referido a la Reforma protestante, fenómeno sin duda significativo, si bien resulta curioso que se conmemore un hecho que separó a la cristiandad 
(es decir, a Europa) frente a otro (1492) que sirvió para unir al planeta y expandir la cultura europea, amenazada hasta entonces en su supervivencia y predominancia por el mundo asiático y árabe.

Como conclusión, cabe observar que un punto en común en la mayor parte de las tesis sobre el origen, construcción y la evolución de Europa será olvidar lo que ha aportado España. Y eso que, aparte de que Tartessos fuera probablemente la primera civilización occidental, la ciudad de Carteia en la bahía de Algeciras fue la primera que otorgó a sus habitantes la "ciudadanía romana" fuera del suelo itálico, un título que, tal como lo concibe Elio Aristides en el siglo II, resulta el antecedente de la "ciudadanía europea" de hoy en tanto reconocimiento legal de la doble pertenencia, idea por cierto propuesta también por el gobierno español de la época. Este "olvido" o simple "borrado histórico" alcanza igualmente a minimizar la importancia decisiva de la gran batalla (30.000 muertos) de Lepanto (1571) que impidió la invasión de Europa por parte del Imperio turco. En otro lugar hemos explicado el origen y consecuencias de esta campaña internacional de desprestigio y ocultación de todas las hazañas y aportaciones protagonizadas por españoles (G. Ibáñez: 2018) ${ }^{4}$.

\section{Fuerzas centrípetas y centrífugas}

La Historia de Europa es la de un continuo movimiento ambivalente y pendular entre las fuerzas centrípetas que han venido empujando hacia la unión del continente y las fuerzas centrífugas que han buscado su división sembrando el conflicto y el enfrentamiento, en ocasiones sangriento, incluso cuando no había motivos para ello (e.g. desencadenamiento de la I Guerra Mundial/ civil europea). Tiene toda su vigencia e interés analizar este proceso pues en estos momentos, tras un periodo centrípeto, que se consolida con la firma del Tratado CECA en París en 1951 y los Tratados de Roma en 1957, vuelven de nuevo las oscuras fuerzas centrífugas a partir de la crisis de deuda, y sobre todo con el Brexit y ahora con la gestión de las consecuencias socioeconómicas de la pandemia. Tanto si leemos a Jorge Santayana como a G.W.F Hegel (ver supra) no cabe duda de que para comprender lo que está sucediendo hoy resulta imprescindible saber lo que ha venido ocurriendo en el pasado.

En el proceso de construcción-desconstrucción europea existen pautas que se repiten, como si de una mano invisible se tratara, sólo que en esta ocasión no

${ }^{4}$ Hay varias causas detrás de la leyenda negra hispanófoba. Basta recordar que España amenazó con convertirse en hegemónica en Europa, en los mares, y en el mundo, siendo además el primer imperio global con presencia en los cinco continentes. Como consecuencia, la mayoría de las naciones con poder suficiente se dedicaron a tratar de arrancarle alguna, sino todas, de sus posesiones y ventajas. Y dos siglos de luchas tampoco se olvidan ni se perdonan, fácilmente (S. Madariaga, 1979, p. 35). Como dicen los anglosajones: "nothing personal, just business". 
es (sólo) el mercado, sino la combinación de inercias e ímpetus político-sociales la que marca un camino que siempre se para en la penúltima casilla, la que nos obliga volver a empezar desde el inicio el juego de la "Eur-oca". La pregunta es si somos esclavos de una condena sin remedio tipo Sísifo o si por una vez nuestros supuestos avances, y una mayor conciencia de las lecciones que ofrece gratis la Historia, nos permitirán parar de subir y bajar la piedra, aunque quepa imaginar a Sísifo feliz una vez que aceptó su destino y la voluntad de los dioses.

Los primeros intentos de unir al continente fueron de tipo imperial. Los europeos estamos orgullosos de nuestro pasado "romano", pero en aquellos días, como también en otros que le siguieron, se trataba de que una parte (Roma, Francia, Alemania...), liderada por personajes de enorme voluntad (César, Constantino, Carlomagno, Napoleón e incluso Hitler...), dominara al resto imponiendo así mismo su cultura y sus leyes. No sabremos ya qué habría pasado si las culturas pre-romanas no hubieran desaparecido por la fuerza del Imperio, aunque también es cierto que Roma (y su derecho) no habría podido tener tanto éxito sin el apoyo de la filosofía griega y la religión judeo-cristiana. En todo caso, la idea de "una Europa" ha convivido permanente con otra de "las Europas", por razones semejantes a las que ya en la época visigótica se hablaba de España y de "las Españas", recogiendo así la existencia de más de una provincia, por de pronto la Citerior y la Ulterior de la época romana, que acabaron siendo Carthaginensis, Tarraconensis, Gallaecia, Lusitania y Baetica. En el caso de Europa, desde que el Imperio romano se dividió en dos, occidente y oriente, asistimos a una Europa que lucha por reunificarse sin conseguirlo del todo. Incluso hoy corremos el riesgo de dar a Rusia y su entorno por perdidos, permitiendo que se inclinen definitivamente a formar una nueva región, Euroasia, que nos retrotraería al pasado, consolidando la división de Europa en dos partes irreconciliables.

Europa también se divide cuando los árabes invaden la península ibérica dejando de ser el continente sinónimo de "Cristiandad". Las intenciones de Abderrahman eran extender sus dominios a Francia y de ahí a toda Europa. Conscientes del peligro, lo que no hizo Europa para defender a España sí lo hizo para defender a Francia, y así Carlos Martel consiguió reunir un gran ejército en el que, junto a francos, combatieron frisios, sajones y alemanes. De esa manera lograron derrotar a los árabes en Poitiers (732), poniendo así término, al menos por un tiempo, a la guerra santa impulsada por Mahoma para conquistar el mundo cristiano. Si bien cuatro años después los árabes invadieron el Languedoc, resistiendo allí unos 20 años, hasta que fueron derrotados definitivamente en 759 por Pepino el Breve. Indro Montanelli ha señalado que $(1966,214,215)$ : "de haber sido derrotados los francos, Europa entera hablaría hoy el árabe, leería el Corán y sus habitantes tendrían al menos dos esposas". No pasó sin embargo eso en España/Hispania cuyos habitantes 
sorprendentemente permanecieron fieles en su gran mayoría a sus raíces cristianas y su/s lengua/s.

Este abandono de España por parte del resto de Europa sigue sorprendiendo pasados los siglos, aunque en realidad no fuera total. Carlomagno consiguió de nuevo reunificar Europa en el año 799 con un imperio que iba desde el Elba a los Pirineos, y desde la llanura del Po al mar del Norte. Ello llevó al sometimiento total de los sajones y su conversión forzosa al cristianismo, bajo el llamado "Capitular sajón" que implicaba optar entre la conversión o morir a mano de la espada, un proceso que sin embargo no ha sido comparado con el papel, mucho más moderado, que desarrollaría posteriormente la Inquisición. Con todo, esta política agresiva y de deportaciones forzosas daría su fruto, pues en 804 Sajonia pasaría a formar parte del Imperio franco y con el tiempo daría lugar a Germania. Pero Carlomagno hizo también un tímido intento de extender sus dominios al sur de los Pirineos en 778. En realidad, no lo hacía pensando en reunificar Europa o la cristiandad, sino principalmente por aumentar su poder e imperio. Llegó a un pacto con el gobernador de Zaragoza Al-Husayn y el de Barcelona Solimán Be Alarabi para apoyar su revuelta contra el emir de Córdoba (es decir árabes contra árabes). Pero Solimán le traicionó y AlHusayn le cerró las puertas, siendo aniquilado el ejército franco en el paso de Roncesvalles, donde murieron numerosos duques y condes, incluido el duque de la marca de Bretaña, Roldán, que daría lugar a la famosa Chanson de Roland; una muestra temprana de la habilidad de los francos para transformar sus derrotas en victorias (otro caso pasados los siglos sería la II Guerra Mundial).

En todo caso, aunque Carlomagno haya pasado a la Historia como constructor de Europa, en realidad acabó siendo el promotor de nuevas divisiones debido a su decisión de repartir entre sus hijos (806) el Imperio que tanto esfuerzo le había llevado construir. No lo logró del todo a causa de la muerte de algunos de ellos, pero lo cierto es que esa costumbre "desintegradora" continuó, consolidándose en el Tratado de Verdún (843), donde Europa quedó dividida en tres partes ( árabe) entre Luis el Germánico, Carlos y Lotario. Esta división sería fuente de constantes guerras por unas fronteras bastante artificiales y que nadie reconocía incluso hasta bien entrado el siglo XX (conflicto sobre Alsacia y Lorena). Sin embargo, con algunos matices acabaría dando lugar a lo que hoy conocemos como Francia, Alemania e Italia.

A la vista de este rápido recorrido histórico, parecería que hasta muy recientemente (Comunidades Europeas/UE) no habría prevalecido una visión transversal de Europa, donde una parte no tratara de dominar e imponerse al resto, salvo que consideremos que el eje París-Berlín sigue jugando hoy ese papel. No obstante, en realidad sí cabe detectar algunos enfoques transversales previos en Europa, como cuando ésta era conocida como un todo bajo el término 
"Cristiandad". O los años en que Carlos V (y I de España) fue emperador, donde no existía una cultura nacional dominante (si bien en los mapas de la "Europa regina" de la época figuraba España como cabeza coronada) e incluso mantuvo la idea de una "Universitas Christiana" pensando que Europa podría sobreponerse a la división de la cristiandad en dos o más partes (católicaluterana-anglicana-ortodoxa) si enfocaba su lucha contra el Turco. No obstante, el viejo emperador encerrado en Yuste acabaría aceptando la inevitabilidad de la división europea -debida a la oposición de Francia, la ambigüedad del papado y las permanentes luchas políticas con coartada religiosa- decidiendo dividir su Imperio entre su hermano Fernando y su hijo Felipe.

En este contexto, resulta curioso que se haya considerado a Lutero como el profeta de la civilización europea-occidental, un precursor, un líder de una verdadera revolución que encontraría su Santo Tomás o su San Pablo en Hegel, quien le otorgaría una mayor organización y altura intelectual al sistema (Castellano: 2016, 16 ss). Un análisis en profundidad de la reforma protestante trasluce que su significado fue menos religioso (las discusiones doctrinales eran corrientes en la época) y más político. Lutero fue instrumentalizado por los príncipes alemanes de la época, que se aprovecharon de su odio personal al Papa para acabar separándose ellos mismos políticamente de la Iglesia de Roma, que era su verdadera intención, y fundar así otras iglesias regionales que ellos pudieran controlar y que sirvieran a los intereses de las incipientes naciones (Castellano: 2016, 158). Se trataba de utilizar a las masas por la vía de la polémica religiosa para lograr un objetivo político: el surgimiento de las nuevas naciones. No es casualidad que la Iglesia anglicana se creara igualmente en 1534, diecisiete años después. Ni tampoco, que en dicho mismo año se fundara la española Compañía de Jesús en París (Montmartre), que entre sus funciones tuvo hacer frente, sobre todo desde el punto de vista intelectual, a dichos movimientos disgregadores. El protestantismo no solo dividió la cristiandad en sentido religioso, sino que significaría la cuna del nacionalismo, encarnado por los mencionados príncipes alemanes y por Inglaterra, donde todavía hoy, sin que nadie lo cuestione, el jefe de la Iglesia "nacional" sigue siendo el jefe del estado o monarca.

A pesar de ello el protestantismo pasará a la Historia como sinónimo de modernidad y eso que la primera fase de apogeo de la civilización moderna occidental tuvo lugar entre el año 1500 y el 1700, bajo la prevalencia y dominio del Imperio español (incluida la Escuela de Salamanca) y, por tanto, de la Iglesia católica, a quien se debe también la creación de las primeras universidades. La segunda fase comenzará a partir de la revolución francesa y norteamericana, donde coinciden grandes aportaciones junto con grandes contradicciones que llegarán a su apogeo en pleno siglo XX. Cuando Max Weber (Die protestantische Ethik und der 'Geist' des Kapitalismus, publicado en 1905) defendió que el 
desarrollo económico de un país se debía a la cultural protestante, olvidó decir que en pleno Renacimiento Alemania estaba bastante menos desarrollada que Italia o España. Por tanto, sobre esta cuestión existe al menos más de un punto de vista. Así, para Novalis, con el protestantismo y el anglicanismo se pone fin a: "una época hermosa, resplandeciente, aquella en la que Europa era un país cristiano, en la que una única Cristiandad habitaba esta parte del mundo humanamente configurada, un único y gran interés común unía las más apartadas provincias de este amplio reino espiritual (...) [pues los protestantes aunque] Formularon un buen número de principios justos, introdujeron gran cantidad de cosas loables y derogaron numerosas prescripciones perniciosas (...) olvidaron el necesario resultado de su proceso: separar lo inseparable (...) escindirse de modo ultrajante de la sociedad cristiana universal, mediante la cual, y en ella sólo, resultaba factible un renacimiento firme y duradero"s.

Más recientemente, Orlando Figes (2020) enlaza la idea de una Europa unida con algo más práctico: la construcción de la primera línea ferroviaria trasnacional entre Colonia y Amberes (1843), a la que seguiría tres años después la línea París-Bruselas (1846) y el papel jugado por una familia de músicos y cantantes españoles, desde el patriarca y compositor Manuel García (1775-1832) hasta sus hijas, demostrando así que las nuevas comunicaciones permitieron el intercambio y viaje continuo de los artistas que pudieron generar una cultura europea transnacional de este a oeste y de norte a sur. Pero es curioso que en ese análisis no se mencione el papel crucial, y también muy práctico, que jugó el camino de Santiago y lo que esta meta llegó a significar para la construcción de Europa. En España finalizaba la tierra conocida, y en Finisterre (y luego en Santiago) acababa un camino que sirvió para fundir culturas, creencias, frustraciones y aventuras, así como para favorecer la apertura de mercados y el surgimiento de una burguesía muy pronto enfrentada a nobles y eclesiásticos (Cortázar: 2008, 38).

Las dos guerras mundiales (guerras civiles europeas) parecieron sellar el límite a la senda de enfrentamiento y división, marcando el camino, que parecía esta vez definitivo, hacia la búsqueda de la unidad; por un lado, para evitar que se repitiera la barbarie entre europeos y, por otro, para hacer frente a los gigantes que surgieron a resultas de la propia debilidad europea (USA y la URSS). Tras la primera gran guerra, en 1924, aparece el Manifiesto paneuropeo impulsado por el conde Coudenhove-Kalergi, que uniría a los países democráticos de Europa, donde por cierto no se incluía ni a Rusia ni a Gran Bretaña. Tras la segunda gran guerra, en 1948, se convocaría un Congreso reunido en la Haya del Movimiento Europeo, cuyo primer logro sería la creación del Consejo de Europa.

\footnotetext{
${ }^{5}$ Georg Philipp Friedrich von Hardenberg (Novalis) "Die Christenheit oder Europa / La cristiandad o Europa (1799)" Araucaria. Revista Iberoamericana de Filosofia, Política y Humanidades, año 19, $\mathrm{n}^{\mathrm{o}} 38$. Segundo semestre de 2017, pp. 11-23, pp. 11 y 14; doi: 10.12795/araucaria.2017.i38.01. https:// revistascientificas.us.es/index.php/araucaria/article/view/4022/3495].
} 
Sin embargo, sería ingenuo ignorar que este proyecto paneuropeo siempre ha tenido los pies de barro. En primer lugar, porque se olvidaba a Rusia, consolidando de esta manera la división de Europa en dos partes: occidental y oriental (o euroasiática). En segundo lugar, porque la postura de los países europeos hacia la integración supranacional en unos casos era movida más por interés circunstancial que por sentimiento auténtico. Curiosamente, a pesar de la barrera física que forman los Pirineos, no puede separarse el pensamiento español y el de sus escritores de una fuerte implicación europea (Díez del Corral: 1974, 123-146). Podríamos haber mirado fácilmente hacia África, con quien tenemos casi frontera, pero no lo hicimos ${ }^{6}$. Otros, sin embargo, que no tenían ocasión de elegir por encontrarse geográficamente en el medio del continente, sí lo hicieron mucho y más que nosotros: "Alemania podría afrancesarse o italianizarse, pero no europeizarse; Francia será capaz de britanización, pero no de europeización" (Ibid, 123). Por tanto, el europeísmo de algunos es de necesidad o de cálculo interesado. El nuestro lo ha sido siempre por elección, por vocación. Lo que hicimos, lo hicimos no solo en nombre e interés de España, sino del cristianismo y de Europa entera. Por el contrario, aunque la salida de Gran Bretaña pueda explicarse desde muchos puntos de vista, uno es que cuando un barco se hunde siempre hay algunos que son los primeros en querer abandonarlo. El europeísmo británico lo ha sido siempre por cálculo interesado ("nothing personal, just business"); si la UE hubiera cumplido las expectativas que alimentaron la creación del mercado único y el euro, Gran Bretaña seguiría dentro.

En resumen, hoy Europa, una vez más, olvidadas las dos grandes guerras y el éxito que supuso la creación de la CEE/UE, está de nuevo en peligro de desintegración (¿y enfrentamiento?), pero más por su debilidad interna que por amenazas externas.

\section{El futuro de Europa en peligro: los enemigos internos}

\section{1. ¿Foco atractivo o modelo en decadencia?}

Europa ha sido capaz de hacer lo mejor (humanismo, civilización, arte) y lo peor (guerras cruentas, ideologías autoritarias, la tecnología puesta al servicio de la tortura y la muerte), como trasunto del ser propio humano, bueno y malo

\footnotetext{
${ }^{6}$ Basta mirar a los estudios recientes de genética de poblaciones (Gómez Moreno: 2017, 398-400). Casi tres cuartas partes de la población masculina de la Península Ibérica, Francia, Gran Bretaña e Irlanda, tiene idéntico grupo genético, el R1b, característico de la Europa Occidental. Y las mujeres de España (60\%) y Europa comparten la elevada frecuencia del haplogrupo $\mathrm{H}$, característicamente europeo, Por el contrario, no hay corte genético más brusco en todo el globo terráqueo que el del Estrecho de Gibraltar, a pesar de la corta distancia que separa la Península Ibérica de Marruecos.
} 
al mismo tiempo (Fromm: 2003). Un mal, como ya nos mostraría Homero en la Ilíada, que forma parte inevitable del ser humano y del mundo, y que a lo que más que podamos aspirar es a que su "permanencia ontológica" sea susceptible de acompañarse de un creciente progreso moral (Hermosa: 2019, 70 y 73). Nuestros errores y horrores, por ejemplo con la época colonial, han llevado a ensalzar la multiculturalidad y denigrar el ser tildados de eurocéntricos, lo que ha convertido en estrambótica la posibilidad de defender los valores del legado europeo y mucho menos poder imponerlos a quienes quieren venir a vivir con nosotros ${ }^{7}$. Mientras, hay quien sostiene que hoy ya no cabe hablar de civilización europea-occidental, pues en realidad ésta (y todas las demás) se habrían disuelto en una única civilización global, fruto de la interconexión y las nuevas tecnologías (Harari: 2018, 116 y 117).

En este contexto, ¿sigue teniendo sentido defender a Europa como algo singular? ¿Tiene todavía Europa algo que aportar al mundo o nos resulta indiferente que se disuelva en un caos de confusión? Hemos tenido sin duda nuestras sombras, como también las han tenido otros, pero sin las aportaciones de Europa el mundo sería otro, si bien no necesariamente mucho mejor. La cultura europea todavía puede colgarse orgullosa grandes medallas: en la música (Mozart, Beethoven, Bach, Haydn, Verdi...), en la literatura (Shakespeare, Cervantes, Dante, Lope...), en la pintura y escultura (Miguel Ángel, Goya, Picasso, El Bosco, Rafael...) e incluso en su base religiosa cristiana (los diversos santos y santas, místicos y grandes teólogos).

$\mathrm{Y}$ sin embargo, lo cierto es que a finales del siglo XIX y sobre todo a principios del siglo XX el modelo europeo comienza a dar señales de agotamiento debido fundamentalmente a dos fenómenos concomitantes: el surgimiento de los extremismos políticos (comunismo, nazismo y fascismos) y la sucesión de dos guerras mundiales (o guerras civiles europeas), que dejaron el mayor número de muertos de la historia, a pesar de que el lanzamiento de dos bombas nucleares no fuera una iniciativa europea. A ello se une la crítica ya clásica, recogida entre otros por el sociólogo francés A. Touraine (2000), de una modernidad que ha sometido todo a la racionalización y a la normalización, provocando un mundo frágil que lleva al desencanto. O la de Heidegger (1984), de un pensamiento occidental que ha perdido (de nuevo) sus raíces. Hoy pocas

\footnotetext{
${ }^{7} \mathrm{Si}$ bien esta catarsis cultural no se ha llevado a cabo en todos los países europeos por igual, hasta el punto de que la leyenda negra de Europa en África está por escribir. Por ejemplo, de la figura de Churchill nos queda su papel jugado para derrotar a Hitler, olvidando sus excesos previos en África. Igualmente, suele pasar desapercibido el comportamiento de una pequeña potencia como Bélgica (hoy sede de las instituciones de la UE) en el llamado Estado Libre del Congo, donde se cortaban brazos como castigos a los campesinos y se arrasaban aldeas enteras. Entre 1885 y 1908 perdieron la vida entre 6 y 10 millones de congoleses. A pesar de lo cual su máximo responsable, el rey Leopoldo II, que figuraba entonces como único propietario de todo un país africano, goza de una estatua ecuestre en un parque de Bruselas y ha sido defendido por varios historiadores. Así, una biografía escrita en los años 30 proclama: "Jugée avec le recul des années, dans ses mobiles comme dans ses réalisations, la politique coloniale de Léopold II est loin de mériter une condamnation” (Lichtervelde: 1935, 297).
} 
personas, y menos intelectuales, ven el futuro de Europa con optimismo (por todos, Finkielkraut: 1987). Cada vez son más las voces que reconocen que se encuentra en un periodo de decadencia, aunque sigamos siendo (¿por cuánto tiempo?) un faro atractivo para otros. La crisis es multicausal. Europa no ha cumplido las expectativas de crecimiento y progreso económico y social que prometían el mercado único y el euro. Pero también afecta a la calidad de la convivencia, a la salud mental y social: una sociedad que presume de ser (todavía) el primer mundo, pero donde el consumo de drogas, somníferos y ansiolíticos crece cada día, nuestros jóvenes se inician antes en el consumo del alcohol y la depresión se ha consolidado como la enfermedad que caracteriza a toda una época.

¿Qué nos está pasando? En realidad, nada nuevo. El historiador italiano Amiano Marcelino ha defendido que el Imperio romano entró decadencia por la indolencia, degradación y hedonismo de los romanos, por haberse apartado de las virtudes que habían engrandecido Roma (citado por Galán: 2012, 501): el poder que daba el prestigio de ser justo gobernando (auctoritas), la dignidad (dignitas), la tenacidad (firmitas), la austeridad (frugalitas), la laboriosidad (industria), la buena educación (comitas) y la discreción (prudentia). A las que cabría añadir la lealtad, el cumplimiento de sus deberes hacia lo divino, padres, familiares y antepasados (pietas), que formaba igualmente parte inmanente al "ser" romano. Pero no solo los romanos también los griegos, en su época de esplendor, tenían claras cuáles eran las virtudes que debería reunir un buen ciudadano y las enseñaban en las escuelas a través del estudio de las vidas ejemplares de sus grandes personajes. En el mundo romano se distinguía entre virtudes personales (a las que todo ciudadano debía aspirar) y virtudes públicas (que permitían funcionar a la sociedad). La decadencia de Grecia y Roma no fue mérito de los bárbaros sino consecuencia de dejar de representar sus virtudes clásicas.

\subsection{Nuevas/viejas fuerzas internas desintegradoras}

¿No le está pasando algo parecido a Europa? Si la actual decadencia de Europa se consolida no será culpa principal de ningún adversario o agente externo, sino de nuestros enemigos internos, los más terribles de todos porque casi siempre pasan desapercibidos y no estamos preparados para el fuego presuntamente amigo ${ }^{8}$. Todos los sistemas acaban fracasando o entrando en fase de deterioro, no tanto por la presión o ataque de adversarios o competidores externos cuanto por las carencias o deficiencias internas de cada organización, sociedad o incluso a nivel personal. El enemigo interno es siempre el más

\footnotetext{
${ }^{8}$ Ver Alberto G. Ibáñez, "El enemigo interno de Occidente: una hidra de cinco cabezas", El Cronista del Estado Social y Democrático de Derecho (septiembre 2018), núm. 76, pp. 60-69.
} 
peligroso porque no se le suele prestar excesiva atención, incluso en los propios planes estratégicos de seguridad y defensa. Y eso a pesar de que la propia Biblia nos enseña que el primer conflicto violento sobrevino dentro de la familia, entre hermanos (Caín y Abel) y no ganó precisamente el bueno.

Un primer enemigo interno de Europa es el proceso de deconstrucción del individuo, así como la creciente fragmentación política y social ${ }^{9}$. Hemos olvidado que la vida es lucha por lo que ya no nos preparamos para vencer la presión, cayendo así en un estado de de-presión, aturdimiento, frivolidad, despreocupación, permisividad exagerada, ausencia de límites o sentido de la irresponsabilidad (G. Ibáñez: 2020). En ese sentido apuntan tanto el historiador anglo-español F. Fernández-Armesto (2010), el filósofo y sociólogo francés G. Lipovetsky (2016) y más recientemente J. Haidt y G. Lukianoff (2019). Asistimos a una relajación de costumbres, valores y exigencias desde que el virus cultural posmoderno se extendió por las venas de un tejido social cada vez más licuado. Sin solidez hay que dar continuamente brazadas para no ahogarse, sin saber dónde nos lleva la corriente, mientras la posmodernidad crea nuevas inquisiciones que imponen al discrepante la pena del destierro cultural o el silencio.

El concepto del "deber" ha entrado en crisis, siendo sustituido por los más líquidos y gaseosos de autorrealización, derecho a pasarlo bien o asertividad, todo ello en un clima de autocomplacencia, mientras las virtudes se reducen a poco más que se ser solidario o empático (Y. Dror, 1994, pp. 180, 187). En la filosofía colectivista los deberes se les exige a los otros (los ricos, por ejemplo), pero no a sí mismos, contraponiendo así derechos de unos frente a deberes de otros; solo quedaría el deber de obediencia y fidelidad al líder del grupo al que cada uno pertenece. Por su parte, F. Fukuyama ha utilizado el término "megalotimia" (aspiración a ideales superiores), de reminiscencias platónicas, para constatar que la sociedad occidental proporciona progreso material y seguridad, pero al precio de crear "hombres sin pecho", que más allá de la satisfacción actual "no tienen nada en su núcleo, ni metas ni ideales más elevados por los que estén dispuestos a luchar y sacrificarse" (2019, p. 15).

Hemos dejado de profundizar en las causas de los problemas para enfocarnos en el procedimiento deliberativo, pero la ética procedimental se ha demostrado banal e incapaz de resolver las causas profundas de nuestras principales amenazas. El debate social vive dentro de una contradictio in terminis interminable. Hoy el saber anda dividido en miles de escuelas y disciplinas, cada una tratando de cavar su pozo más profundo, sin salir arriba

\footnotetext{
${ }^{9}$ Existen otros enemigos internos en los que no entraremos por razones de espacio: e.g, el lado oscuro de la innovación y la tecnología que puede llevarnos a la deshumanización y una crisis económica que amenaza con convertirse en permanente Sobre el primer aspecto ver: Alberto G. Ibáñez, "De la tecnología a la tecnolocracia: ¿fortaleza o amenaza?”, El Cronista del Estado Social y Democrático de Derecho, nº 81, sept. 2019, 52-61.
} 
de vez en cuando para ver la luz y qué hacen el resto, lo que lleva a la creación de realidades y percepciones separadas.

Otra de las consecuencias de este proceso es que la propia democracia, aportación principal de la cultura europea, se encuentra hoy en crisis, hasta el punto de que algunos la dan ya por perdida (E. Todd, 2008). Tzvetan Todorov menciona como "enemigos íntimos" de la democracia al mesianismo, el ultraliberalismo y el populismo (2012). Más allá de que quepa contraponer al ultraliberalismo el ultraestatalismo, la democracia no puede evitar por sí misma el deterioro de las sociedades donde opera mientras sus enemigos se aprovechan precisamente de las libertades democráticas para destruirla. Incluso los ciudadanos que viven bien en las sociedades democráticas pueden alzarse contra ella, entre otras cosas para paliar su aburrimiento (Mounk, 2019, p. 275). Se produce una banalización del gobierno mientras los partidos políticos actúan en un pantano ideológico desconectados de la realidad, donde la competición política deriva hacia el teatro y el espectáculo (Mair, 2013, p. 60).

Todo ello acaba produciendo una suerte de oclocracia populista de la que se aprovecha, entre otros, el nacionalismo disgregador que busca acabar con Estados-nación con siglos de historia, poniendo al mismo tiempo en jaque la seguridad, unidad y estabilidad de toda Europa ${ }^{10}$. Resulta paradójico que gran parte de lo que ocurre en nuestras sociedades e incluso en la política mundial se deba a la "demanda de reconocimiento de identidad" (F. Fukuyama, 2019, p. 17). El ser humano busca desesperadamente su identidad adornándose de multitud de etiquetas, pero las identidades no son necesariamente fijas ni están definidas por el azar del nacimiento, ni es lo mismo si se utilizan para dividir (separatismo y/o sectarismo) que para integrar (comunidad nacional o supranacional). De hecho, esta segunda función podría ser un remedio contra el creciente populismo (Fukuyama, 2019, p. 197).

En resumen, no podemos seguir actuando como si nuestra propia existencia no estuviera en peligro, como si los movimientos radicales de uno y otro signo fueran a desaparecer por arte de magia. Europa corre peligro cierto de quedar difuminada o diluida dentro de un puzle lleno tal vez de buenas intenciones, pero maniatadas por falta de realismo o intereses contrapuestos. El antiguo gran buque colectivo puede quedar en botín o mero bote comparsa de los tres grandes.

10 Ver Alberto Gil Ibáñez, "Why Nations Fail. The Relevance of Stability and Culture for European and Global Security”, en Ramírez y Biziewski: 2019, 123-138. 


\section{Hacia un nuevo renacimiento cultural: el valor de una Europa con valores}

¿Cómo evitar este futuro distópico? Las causas detrás de la caída y éxito de una sociedad, o de una persona, son complejas, pero entre ellas aparece sin duda la dimensión cultural. Por de pronto, las creencias culturales (cultural beliefs) o el universo de valores sociales influyen en las decisiones económicas (e.g. North: 2005). Europa, gracias a los filósofos de la sospecha, logró tal vez matar a Dios, pero no ha conseguido sustituir las virtudes clásicas por otras dignas de formar una verdadera ética pública, capaz de preparar a las nuevas y viejas generaciones para enfrentarse y superar los retos y amenazas, que hoy como ayer, se presentan en cualquier recorrido vital. Hace años A. Macintyre (1987) describió este proceso señalando que en las sociedades contemporáneas ya no era posible hablar de virtudes religiosas, pero tampoco de las aristotélicas, fusionadas en realidad por Santo Tomás. Esta des-moralización produce una sociedad que carece de consenso moral auténtico donde cualquier obligación política deviene sistemáticamente confusa $(1987,312)$. Por ello Macintyre acababa proponiendo la necesidad de reactualizar el modelo moral aristotélico.

¿Pero cabe hoy enumerar un conjunto de virtudes cívicas? El concepto más habitual de virtud cívica, en sentido republicano, es precisamente la capacidad de sacrificar los intereses particulares en aras del interés común (Wood: 1969). Sin embargo, si queremos construir sociedades con distintas concepciones flotando en permanente conflicto (latente o patente) no resuelto, la idea de bien común correrá el riesgo de difuminarse o acabar convirtiéndose en un reto inalcanzable. Un mínimo común denominador es necesario para que una sociedad pueda funcionar. Europa debe decidir qué valores comunes representa y quiere mantener. La democracia y los derechos humanos forman parte del modelo, pero no bastan. Debemos concretar qué otras ideas-fuerza constituyen nuestra esencia, la que asegura la ambición de mejora constante y el progreso social y económico. No se trata de volver al eurocentrismo, pero sí de hacer frente al rearme cultural que otras potencias están emprendiendo sin complejos.

Sin saber qué o quiénes somos y qué o quiénes queremos ser difícilmente podremos dialogar con otros, ni mucho menos liderar o servir de referentes globales a nadie. Lo más probable es que poco a poco vayamos difuminándonos, poniendo en peligro la multiculturalidad entendida en sentido global. ¿Cabe hablar todavía de una cultura europea? ${ }^{11}$. Denis de Rougemont definía a Europa como una aventura decisiva para toda la humanidad, más antigua que

${ }^{11}$ Ver Alberto G. Ibáñez, “¿Existe (o debe existir) una cultura europea? [https://blog.idee.ceu. es/2016/11/02/existe-o-debe-existir-una-cultura-europea/]. Ver también: Alberto G. Ibáñez, "Hacia un renacimiento cultural: ¿Procedimientos o valores compartidos?”, en Itziar García y Xavier Peytibi (coord.) Cómo la UE puede volver a enamorar, Monográfico 3, Revista Politics Magazine (2017) (https://beersandpolitics).

Araucaria. Revista Iberoamericana de Filosofia, Política, Humanidades y Relaciones Internacionales, año $22, \mathrm{n}^{\circ} 45$. Tercer cuatrimestre de 2020. Pp. 527-548. ISSN 1575-6823 e-ISSN 2340-2199 https://dx.doi.org/10.12795/araucaria.2020.145.22 
sus naciones, de vocación no solo universal, sino universalizante, cuya base habría sido el cristianismo y el liberalismo, como fundamento de la dignidad y la libertad del ser humano (Rougemont: 2007, 19 y 20). Por de pronto, no parece que convenga tirar por la borda los ideales de la Ilustración -razón, ciencia, humanismo y progreso-, por más que puedan/deban ser reformulados y adaptados al mundo de hoy (S. Pinker, 2018). La confluencia de la herencia del Imperio romano (Roma), la filosofía griega (Atenas) y la religión judeocristiana (Jerusalén) ha sido asimismo fructífera a pesar de nuestros errores (Habermas: 2001).

Si Europa entra definitivamente en decadencia o desaparecen sus valores, todos saldrán perdiendo. Mientras nuestros valores se debilitan o difuminan, otros se van imponiendo, llenando el vacío como las leyes de la física nos enseñan, pero con valores potencialmente contrarios a los nuestros. Europa no puede quedarse en mero parque temático, balneario o aseguradora social universal. No es solo que esto nos lleve a la irrelevancia, es que sencillamente resulta letal. Estamos a tiempo de evitarlo. Para ello deben ponerse todos los medios institucionales, mediáticos, intelectuales y legales a la tarea de reconstrucción cultural. Si Europa quiere contribuir realmente a la paz mundial y una globalización justa, debe superar los discursos ingenuos y recuperar el ingenio que le permita, una vez más, reinventarse a sí misma permitiendo un nuevo Renacimiento cultural, sólido, no limitado a lo tecnológico o a la inteligencia artificial, sino que abarque el arte, la filosofía, la moral, la política, la seguridad y la ética.

La solución no es que todo el mundo venga a vivir a Europa, sino que todo el mundo pueda vivir como viven los europeos sin necesidad de abandonar su país de origen. La receta pasa una vez más por "más Europa", solo que esta vez a escala global. Necesitamos europeizar la globalización. Abrir los mercados entre agentes que no juegan con las mismas reglas no es liberalismo, sino ingenuidad. Sin unas reglas claras y comunes en términos de protección social y derechos humanos no puede haber globalización, o la podrá haber, pero Europa no sobrevivirá. Algo parecido ocurre cuando se equipara globalización con la necesaria desaparición de los Estados nación: "Es un error pensar que los Estados son entidades obsoletas y que deberían reemplazarse por organismos internacionales, porque nadie ha podido encontrar aún la forma para que en [estos] funcione la rendición de cuentas propia de la democracia" (F. Fukuyama, 2019, pp. 152, 153).

Hoy como ayer, toda ética (como la realidad) tiene sus límites (nulla ethica sine finibus), la virtud busca un punto medio (la sensatez) que se aparte de los excesos (la radicalidad). Ha llegado el momento de ser responsables sin ser ingenuos. Precisamente los tiempos de pandemia, biológica y moral, que vivimos pueden ser l'occasione, en el sentido que le daba Maquiavelo, 
para este renacer cultural. Como ocurriera con la peste que asoló hace siglos la civilización ateniense transformándola en el reino de la necesidad y despertándola así del hechizo de ilusiones que matan: la búsqueda de la utopía y del arquetipo del hombre bueno y/o racional (Hermosa: 2019, 116-119). Un nuevo realismo, una bajada a la tierra que puede servir paradójicamente de base para componer una nueva esperanza.

Combatir el eurocentrismo no puede llevar a destruir la cultura europea. La vida es cambio, pero también permanencia. Lo nuevo no es bueno por ser nuevo, sino porque puede mejorar lo anterior. Mientras no consigamos una carta de presentación sólida en el mundo, cada día jugaremos un papel más irrelevante permitiendo que se imponga la triada internacional -China, EE.UU. y Rusia-, encantada de que Europa quede fuera de juego, instalada en la inane retórica y su poder "soft": líquido y gaseoso. Si queremos sobrevivir solo cabe plantear un renacimiento cultural que aspire no solo a mejorar nuestras sociedades, sino a servir de referente para otros. Hoy la cuestión, una vez más, es ¿ser o no ser? ¿Estaremos a la altura que los tiempos demandan? O, en términos más prácticos, ¿en qué medida la UE puede ser el "poder ejecutivo", el impulsor y generador de este "renacimiento cultural" que estamos proponiendo? 


\section{Referencias bibliográficas:}

Castellano, Danilo: Martín Lutero. El canto del gallo de la Modernidad, ed. Marcial Pons, Madrid, 2016.

Díez del Corral, Luis: El rapto de Europa, ed. Alianza, Madrid, 1974

García de Cortázar, Fernando: Breve historia de la cultura en España: un viaje por la cultura a través de las ciudades, ed. Planeta, Barcelona, 2008.

Elías, Norbert: El proceso de la civilización: investigaciones sociogenéticas y psicogenéticas, ed. Fondo de Cultura Económica, México, 2016.

Eslava Galán, Juan: Historia de España contada para escépticos, ed. Planeta, Barcelona, 2012 (13 ${ }^{\text {a }}$ reimpresión, $1^{\text {a }}$ edición de 2005)

Gómez Moreno, Ángel: La huella del león y el Indovinello veronese en La Mancha (Historia, cultura oral, etnografía y genética de poblaciones), ed. Universidad de Granada, 2017.

Fernández-Armesto, Felipe: 1492: El nacimiento de la modernidad, ed. Debate. Barcelona, 2010

Figes, Orlando: Los europeos. Tres vidas y el nacimiento de la cultura cosmopolita, ed. Taurus, 2020

Finkielkraut, Alain: La Défaite de la pensé, ed. Gallimard, París, 1987.

Fromm, Erich: Ética y psicoanálisis, Fondo de Cultura Económica, México, 2003

Fukuyama, Francis: Identidad. La demanda de dignidad y las políticas de resentimiento, ed. Deusto, 2019

G. Ibáñez, Alberto: La leyenda negra. Historia del odio a España, ed. Almuzara, Córdoba, 2018

G. Ibáñez, Alberto: La guerra cultural. Los enemigos internos de España y Occidente, ed. Almuzara, Córdoba, 2020

Gray, John: Misa negra: La religión apocalíptica y la muerte de la utopía, ed. Paidós, Barcelona, 2008

Habermas, Jürgen: Israel o Atenas. Ensayos sobre religión, teología y racionalidad, ed, Trotta, Madrid, 2001

Haidt, Jonathan y Likianoff, Greg: La transformación de la mente moderna. Cómo las buenas intenciones y las malas ideas están condenando a una generación al fracaso, ed. Deusto, Barcelona, 2019

Harari, Yuval Noah: 21 lecciones para el siglo XXI, ed. Debate, Barcelona, 2018 Heidegger, Martin: Early Greek Thinking. The Dawn of Western Philosophy, ed. Harper \& Pow Publishers, San Francisco, 1984

Hermosa, Antonio: El hombre tras los hechos. Naturaleza humana y politica en la historiografía clásica, ed. Athenaica, Sevilla, 2019

De Lichtervelde, Louis: Léopold II, ed. L’ Édition Universelle/Librairie Plon, Bruselas/Paris, 1935, 4ª edición 
Lipovetsky, Gilles: De la ligereza, ed. Anagrama, Barcelona, 2016

Macintyre, Alasdair: Tras la virtud, ed. Crítica, Barcelona, 1987

De Madariaga, Salvador: España. Ensayo de historia contemporánea, ed. Espasa-Calpe, Madrid, 1979 (14 a edición)

Mair, Peter: Gobernando el vacío. La banalización de la democracia occidental, ed. Alianza Editorial, 2013, Madrid.

Marías, Julián: España inteligible. Razón histórica de las Españas, ed. Alianza, Madrid, 2010.

Von Martin, Alfred: Sociología de la cultura medieval, ed. Instituto de Estudios Políticos, Madrid, 1970 ( $2^{\mathrm{a}}$ edición, $1^{\mathrm{a}}$ edición de 1954)

Martín Ramírez, Jesús y Biziewski, Jerzy (eds.): Security and Defence in Europe, ed. Springer, Cham (Suiza), 2019.

Montanelli, Indro y Gervasso, Roberto: Historia de la Edad Media, ed. Plaza \& Janés, Barcelona 1966

Mounk, Yascha: El pueblo contra la democracia. Por qué nuestra libertad está en peligro y cómo salvarla, ed. Paidós, Barcelona, 2018.

North, Douglas: Understanding the Process of Economic Change, ed Princeton University Press, Princeton, 2005

Padgen, Anthony: Mundos en guerra. 2500 años de conflicto entre Oriente y Occidente, ed. RBA, Barcelona, 2011

De Rougemont, Denis: Tres milenios de Europa. La conciencia europea a través de los textos: de Hesíodo a nuestro tiempo, ed. Ezaro, Madrid, 2007.

Todd, Emmanuel: Après la Démocratie, ed. Gallimard, París, 2008

Todorov, Tzvetan: Los enemigos íntimos de la democracia, ed. Galaxia Gutenberg/Círculo de Lectores, Barcelona, 2012

Touraine, Alain: Crítica de la modernidad, ed. FCE, México, 2000.

Wood, Gordon: The Creation of American Republic 1776-1787, University of North Carolina Press, 1969. 